\title{
FLUE GAS LOW TEMPERATURE HEAT RECOVERY SYSTEM FOR AIR-CONDITIONING
}

\author{
Nirmal Sajan ${ }^{1}$, Ruben Philip ${ }^{2}$, Vinayak Suresh ${ }^{3}, V_{i s h n u ~} \mathbf{M}^{4}$, Vinay Mathew John ${ }^{5}$ \\ ${ }^{1}$ UG Student, Department Of Mechanical Engineering, Saintgits College of Engineering, Kottukulam Hills, \\ Pathamuttom P. O, Kottayam-686532, Kerala, India \\ ${ }^{2} U G$ Student, Department Of Mechanical Engineering, Saintgits College of Engineering, Kottukulam Hills, \\ Pathamuttom P. O, Kottayam-686532, Kerala, India \\ ${ }^{3} U G$ Student, Department Of Mechanical Engineering, Saintgits College of Engineering, Kottukulam Hills, \\ Pathamuttom P. O, Kottayam-686532, Kerala, India \\ ${ }^{4}$ UG Student, Department Of Mechanical Engineering, Saintgits College of Engineering, Kottukulam Hills, \\ Pathamuttom P. O, Kottayam-686532, Kerala, India \\ ${ }^{5}$ Assistant Professor, Department Of Mechanical Engineering, Saintgits College of Engineering, Kottukulam Hills, \\ Pathamuttom P. O, Kottayam-686532, Kerala, India
}

\begin{abstract}
Huge amount of energy wasted through the flue gas in thermal power station causes great concern in recent years. Discharging hot flue gas in the environment is not only a wastage of energy but also increases the rate of global warming. Efforts are given world -wide to harness the energy for useful purposes. In this work, the waste heat of flue gas in a $350 \mathrm{MW}$ thermal power plant is utilized in vapor absorption air conditioning plant. Gas to liquid multi-pass cross flow heat exchanger that have been placed in the existing space between boiler and chimney. The dimensions of the finally selected heat exchanger are $0.106 \mathrm{~m} \times 2.4 \mathrm{~m} \times 3.4 \mathrm{~m}$. The number of pipes required for the heat exchanger is found to be 12 using iteration method and temperature of water at the outlet of last pipe is $101.1^{\circ} \mathrm{C}$. The extracted energy from the flue gas is used to heat water to be utilized in the generator of a vapor absorption refrigeration system that has produced a refrigerating capacity of 70 TR. approximately. Due to the corrosive nature of flue gas, heat recovery is confined up to the acid dew point temperature of the flue gas. Suitable software is used to find out the detailed design parameters of Gas to liquid multi-pass cross flow heat exchangers. Out of many feasible designs of heat exchangers, the most economic design is selected as the final design.
\end{abstract}

Keywords_Air Conditioning; Flue Gas; Heat Exchanger; Heat Recovery; Vapour Absorption Machine

\section{INTRODUCTION}

Waste heat is heat, which is generated in a process by way of fuel combustion or chemical reaction, and then dumped into the environment even though it could still be reused for some useful and economic purpose. The essential quality of heat is not the amount but rather its value. The strategy of how to recover this heat depends in part on the temperature of the waste heat gases and the economics involved. Large quantity of hot flue gases is generated from Boilers, Kilns, Ovens and Furnaces. If some of this waste heat could be recovered, a considerable amount of primary fuel could be saved. The energy lost in waste gases cannot be fully recovered. However, much of the heat could be recovered and loss minimized by adopting suitable measures.

Depending upon the type of process, waste heat can be rejected at virtually any temperature from that of chilled cooling water to high temperature waste gases from an industrial furnace or kiln. Usually higher the temperature, higher the quality and more cost effective is the heat recovery. In any study of waste heat recovery, it is absolutely necessary that there should be some use for the recovered heat. Typical examples of use would be preheating of combustion air, space heating, or pre-heating boiler feed water or process water. With high temperature heat recovery, a cascade system of waste heat recovery may be practiced to ensure that the maximum amount of heat is recovered at the highest potential. Main objective of this work is to utilize the waste heat available in exhaust gases coming out of the Boiler of a thermal power plant. It also intends to use the waste heat available to run a Vapour Absorption Refrigeration System which replaces existing Vapour Compression Refrigeration System which is present in the administrative block of the plant. This work also aims in replacing Freon-12 refrigerant which causes ozone depletion and to reduce the temperature of exhaust gas emitted to the atmosphere which causes global warming.

\section{METHODOLOGY}

This work mainly focus only on the heat recovery from the flue gas in order to run the Li-Br VAM which is having a cooling capacity of $70 \mathrm{TR}$. Temperature of the flue gas available is very low and is about $125^{\circ} \mathrm{C}$. Since the temperature of the flue gas available is very low compared to other power plants, only single effect VAM can be used for this air conditioning purpose. Commercially available single 
effect VAM does not require very high temperature and works on the temperature in the range $80-120^{\circ} \mathrm{C}$ and its COP varies from 0.6 to 0.8 . COP of VAM chosen is 0.7 .

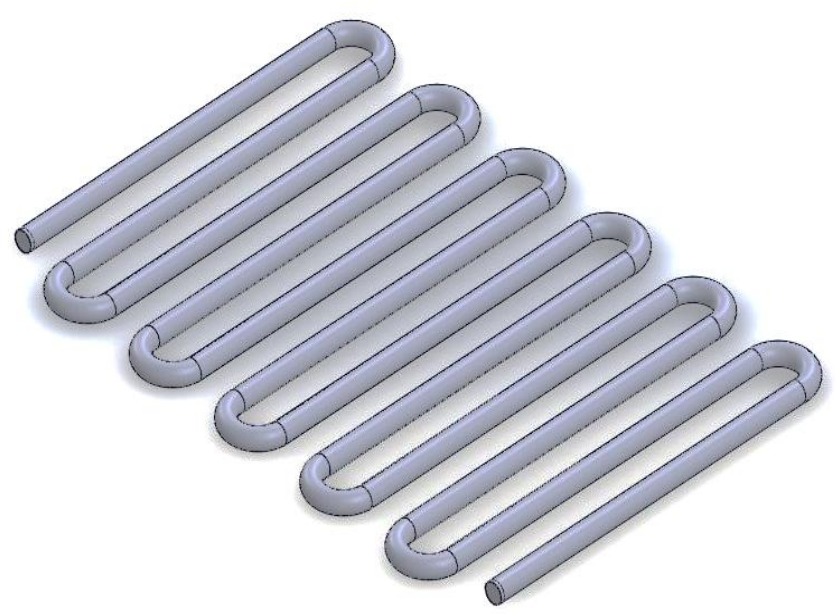

Fig. 1. Isometric view of the flue gas low temperature heat recovery system

In order to produce $70 \mathrm{TR}, 350 \mathrm{KW}$ of heat is supplied to the generator of the VAM. So we designed a Multi-pass Gas to Water heat exchanger to recover waste heat from flue gas to produce Air conditioning effect. Shape of the heat exchanger is selected as serpentine and contains 12 pipes each of $10 \mathrm{~cm}$ diameter. The diameter of the pipe is selected based on the predetermined calculations. Fig. 1. shows the model of the heat exchanger used for this purpose. The 1:1 model of the heat exchanger as well as the water flow simulation was done using Solidworks software. The flow analysis through the tubes as well as the optimization of the number of the tubes was done using ANSYS FLUENT software on a 1: 10 model of the heat exchanger using iteration method. Only a single pipe is considered for analysis because the dimensions of each of the pipe as well as the properties of flow through each of the pipes are the same.

Before finding the outlet water temperature of the heat exchanger using ANSYS Fluent Software following assumptions are considered regarding the flow of water through the heat exchanger and they are,

- Fully developed flow

- Steady flow

- Incompressible flow

- Laminar flow

- There will be perfect mixing of different layers of water occurring at the bend of pipes in heat exchanger.

In this iteration method, the input temperature of water passes to the first pipe of heat exchanger is taken as ambient temperature of $300 \mathrm{~K}$ and its corresponding output temperature is found out by taking the arithmetic average of temperatures of different layers at the outlet of the pipe available using the ANSYS software. At the bend of the first pipe we assumed that perfect mixing of different layers of water is occurred so as to get a uniform water temperature.
Then the outlet water temperature of first pipe of heat exchanger is taken as the input of the second pipe and again the output temperature of water is found out. This process is continued until the desired water output temperature is available at the outlet of the twelfth pipe which is about $374.1 \mathrm{~K}$.

In order to compensate heat losses due to friction due to bend of pipes and pipe wall, required temperature to be supplied to generator in the VAM is taken as $400 \mathrm{KW}$ instead of 350 KW which was the calculated value. This Gas to Water Cross flow Heat Exchanger is to be placed in the space between boiler and chimney. The hot flue gas coming out from boiler passes across the cross flow multi pass heat exchanger and thus heats the water inside the heat exchanger. This flue gas after passing across the heat exchanger will goes out of the chimney. The hot water serves as an input to the Vapour Absorption Machine (VAM) driving Li-Br cycle to produce the desired air conditioning.

Thermal and structural stress effects need not be considered at pressures below $15 \mathrm{~atm}$ or temperatures below $150^{\circ} \mathrm{C}$.Thus the thermal and structural analysis of the heat exchanger is not carried out in this work. But these effects are major considerations above 70 atm or $550^{\circ} \mathrm{C}$ and seriously limit the acceptable materials of the heat exchanger. The common materials used for fabrication of industrial heat exchangers are aluminum, copper, stainless steel and high carbon steel. Since this work involves low temperature heat recovery, stainless steel and high carbon steel are not considered as they are commonly used in high temperature application and are very costly. Table 1 . shows the comparison of properties of Aluminum and Copper which are the possible options for material for the heat exchanger. Since this heat recovery is in the very low temperature and also aluminum is less denser it is the most suitable choice.

Table 1. Comparison of Physical Properties of Materials

\begin{tabular}{|l|l|l|l|}
\hline Material & Density & $\begin{array}{l}\text { Melting } \\
\text { Point }\end{array}$ & $\begin{array}{l}\text { Boiling } \\
\text { Point }\end{array}$ \\
\hline Aluminium & $2.70 \mathrm{~g} \cdot \mathrm{cm}-3$ & $660.32{ }^{\circ} \mathrm{C}$ & $2470{ }^{\circ} \mathrm{C}$ \\
\hline Copper & $8.96 \mathrm{~g} \cdot \mathrm{cm}-3$ & $1084.62{ }^{\circ} \mathrm{C}$ & $2562{ }^{\circ} \mathrm{C}$ \\
\hline
\end{tabular}

The heat exchanger is to be installed in the space between the boiler and chimney. The region is rectangular in cross section with a dimension of $1.25 \mathrm{~m} \times 7.48 \mathrm{~m} \times 17.4 \mathrm{~m}$. The dimensions of the final design of the heat exchanger is $0.106 \mathrm{~m} \times 2.4 \mathrm{~m} \times 3.4 \mathrm{~m}$. The heat exchanger is to be installed in a similar way as that of the radiator in an automobile i.e. each tube pass of the heat exchanger intercepts the flow of the flue gas as it flows from the boiler to the chimney.

\section{ANALYTICAL SETUP}

The system consists of a water reservoir with makeup feed arrangement, pump, heat exchanger, vapour absorption refrigeration system and cooling tower, all of which are connected by pipes of suitable dimensions. Fig. 2. shows the detailed sketch of the proposed system. This paper 
encompasses the design and analysis of the heat exchanger only. The specification of the VAM will be adopted according to the cooling load requirement of the building under consideration and the potential of the flue gas available at the plant. The heat exchanger will be designed to provide the necessary input to the VAM so as to deliver the desired air conditioning effect. The specifications of the remaining part of the system i.e. the reservoir, the pump and the connecting pipes is to be chosen according to the flow requirement of the system.

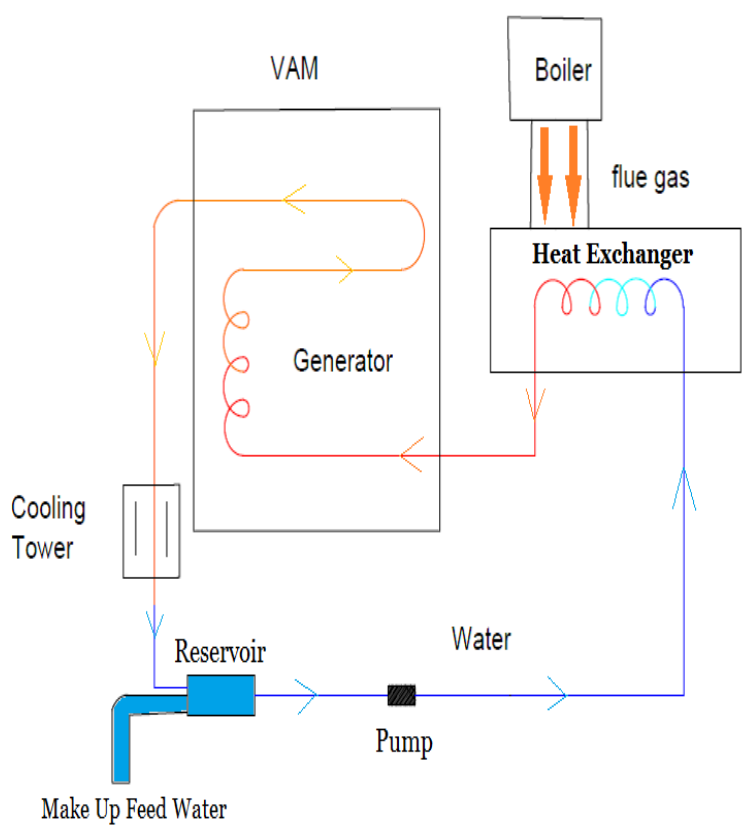

Fig. 2. Detailed sketch of analytical setup

\subsection{Working Process}

The system is proposed for waste heat recovery in a cascade process so that the heat recovery process will be efficient. The working process is intended for maximum heat recovery from the flue gas which is at a temperature of $125^{\circ} \mathrm{C}$, which is a very low temperature compared to that of most of the thermal power plants. At this very low temperature the thermal and structural effects on the heat exchanger to be designed can be neglected. The working fluid selected is water because of its relative abundance and its non-toxic nature along with its high heat capacity.

The process begins when the heat exchanger installed in the space between the boiler and the chimney taps the heat from the flue gas. The flue gas comes out of two of the combustion chambers coupled to each of the two gas turbines installed in the plant. The temperature of the flue coming out of the turbines are of the order of $550 \pm 50^{\circ} \mathrm{C}$. This being a very high temperature is effectively used to generate steam in a HRSG (Boiler). The generated steam is then used to run a steam turbine, thus making the power plant a combined cycle power plant. The temperature of the flue reduces to almost $125^{\circ} \mathrm{C}$ after rejecting heat to the boiler. This flue is made to flow across a multi - pass cross flow heat exchanger. The flue gas after rejecting heat to the heat exchanger passes through the chimney. A pump of predetermined mass flow rate is used to transfer water from a reservoir to the heat exchanger which heats up to the desired temperature through a cascade process involving multi-pass tubes of the heat exchanger.

The heated water is then pushed forward by the pressure existing in the system to the generator part of the VAM which have a capacity of $70 \mathrm{TR}$ and a COP of 0.7 . The water coming out of VAM which is still at a considerable temperature is brought to ambient temperature by passing it through the cooling tower which is already present at the plant. The cooled water is then returned to the reservoir from where it is again pumped by the water pump. A makeup feed water arrangement is also provided with the reservoir to compensate for any losses.

\section{DESIGN DATA}

The heat exchanger is designed according to the VAM requirements. So firstly, the amount of heat that is to be supplied to the generator of the VAM is to be found out. The available inputs are the capacity of the required system and its coefficient of performance.

\subsection{Heat to be supplied to the Generator of VAM}

The heat to be supplied to the generator of VAM can be found out by the equation,

$$
\mathrm{COP}=\frac{\mathrm{Q}_{\mathrm{E}}}{\mathrm{Q}_{\mathrm{G}}}
$$

where $\mathrm{Q}_{\mathrm{G}}$ is the heat to be supplied to the generator of $\mathrm{VAM}, \mathrm{Q}_{\mathrm{E}}$ is the heat absorbed in the evaporator and COP is the coefficient of performance.

\subsection{Outlet Temperature of Flue Gas}

The outlet temperature of the flue gas is found out using the equation,

$$
\mathrm{Q}=\dot{\mathrm{m}} \mathrm{C}_{\mathrm{p}} \Delta \mathrm{T}=\dot{\mathrm{m}} \mathrm{C}_{\mathrm{p}}\left(\mathrm{T}_{\mathrm{in}}-\mathrm{T}_{\text {out }}\right)
$$

where $Q$ is the heat transferred from flue gas to water, $\dot{\mathrm{m}}$ is the mass flow rate of flue gas, $C_{p}$ is the specific heat capacity of flue gas, $T_{\text {in }}$ is the inlet temperature of flue gas and $\mathrm{T}_{\text {out }}$ is the outlet temperature of flue gas.

\subsection{Logarithmic Mean Temperature Difference (LMTD)}

The next important step is finding out the LMTD of the heat exchanger, which is given by

$$
\mathrm{LMTD}=\Delta \mathrm{Tm}=\frac{\Delta T i-\Delta T e}{\ln \frac{\Delta T i}{\Delta T e}}
$$

where,

$$
\Delta T i=\mathrm{T}_{\mathrm{h} 1}-\mathrm{T}_{\mathrm{c} 2}
$$




$$
\Delta T e=\mathrm{T}_{\mathrm{h} 2}-\mathrm{T}_{\mathrm{c} 1}
$$

where $T_{h 1}$ and $T_{h 2}$ are the inlet and outlet temperatures of the flue gas and $\mathrm{T}_{\mathrm{c} 1}$ and $\mathrm{T}_{\mathrm{c} 2}$ are the corresponding values of water.

\subsection{Surface Area of the Heat Exchanger}

Area of the heat exchanger is found out using the equation,

$$
\text { Heat transfer, } \mathrm{Q}=\mathrm{UFA} \Delta \mathrm{T}_{\mathrm{m}}
$$

where, $\mathrm{U}$ is the overall heat transfer coefficient, in $\mathrm{W} / \mathrm{m}^{2}{ }^{\circ} \mathrm{C}$, $\mathrm{A}$ is the surface area of the heat exchanger in $\mathrm{m}^{2}$ and $\Delta \mathrm{Tm}$ is the LMTD in ${ }^{\circ} \mathrm{C}$ and $\mathrm{F}$ is the correction factor.

\subsection{Mass Flow Rate of Water through Heat}

\section{Exchanger}

We know that heat transfer,

$$
\mathrm{Q}=\dot{\mathrm{m}} \mathrm{C}_{\mathrm{pw}} \Delta \mathrm{T}=\dot{\mathrm{m}} \mathrm{C}_{\mathrm{pw}}\left(\mathrm{T}_{\text {out }}-\mathrm{T}_{\text {in }}\right)
$$

where, $\dot{\mathrm{m}}$ is the mass flow rate of water in $\mathrm{Kg} / \mathrm{sec}, \mathrm{Q}$ is the heat transfer in $\mathrm{KW}, \mathrm{C}_{\mathrm{pw}}$ is the specific heat capacity of water, $\mathrm{T}_{\text {in }}$ is the inlet temperature of water in ${ }^{\circ} \mathrm{C}$ and $\mathrm{T}_{\text {out }}$ is the outlet temperature of water in ${ }^{\circ} \mathrm{C}$.

\subsection{Number of Tubes, Diameter and Length of the Pipe}

For a heat exchanger consisting of $\mathrm{n}$ tubes, the total surface area is given by,

$$
\mathrm{A}=\pi \mathrm{dLn}
$$

where, $\mathrm{d}$ is the diameter of the tubes, $\mathrm{L}$ is the length of a single tube.

From the above equation the values of $\mathrm{d}, \mathrm{L}, \mathrm{n}$ are optimised using iteration by taking different values for $\mathrm{d}, \mathrm{n}$ and $\mathrm{L}$ for a constant surface area and the optimised values are;

$\mathrm{d}=10 \mathrm{~cm}$

$\mathrm{L}=2 \mathrm{~m}$

$\mathrm{n}=11$

\subsection{Velocity of Water through the Pipes}

It is clear that mass flow rate,

$$
\dot{m}=\rho A_{c} V
$$

where, $\rho$ is the density of water in $\mathrm{Kg} / \mathrm{m}^{3}, \mathrm{~A}_{\mathrm{c}}$ is the cross sectional area of heat exchanger, in $\mathrm{m}^{2}$ and $\mathrm{V}$ is the velocity of water through heat exchanger in $\mathrm{m} / \mathrm{s}$.

\subsection{Energy Savings}

Power required for operating $\mathrm{VCM}=78.2985 \mathrm{KW}$
Power required for operating $\mathrm{VAM}=2 \%$ of $\mathrm{VCM}=1.566$ KW

Total Power Saved $=78.2985-1.566=76.732 \mathrm{KW}$

Energy saved if air-conditioner works 12 hours per day $=76.732 \times 12=920.784 \mathrm{KWhr}=920.784$ Units/day.

\section{ANALYSIS}

The heat exchanger analysis is being carried out using ANSYS FLUENT software. Although the design involves a multi-pass heat exchanger consisting of twelve pipes, the analysis is carried out only on the first and the last pipe of the heat exchanger. This is because the properties of flue gas flowing through the space between boiler and chimney and the water flowing through the pipe respectively are same for each pipe. The dimensions of the heat exchanger is being scaled down to one - tenth of its original dimensions due to considerable difficulty faced during the analysis of $1: 1$ model of the heat exchanger. But the resulting error will be only one percent. A rectangular control volume of cross sectional area of $30 \mathrm{~cm}^{2}$ is also considered which encloses the pipe. The flow analysis of both the cold fluid and the hot fluid is being carried out in the control volume considered.

\subsection{Velocity Analysis}

Since the velocity of flow of flue gas across the heat exchanger and the velocity of water flowing through each pipes are the same, only a single pipe including the control volume is being analysed. The velocity of flow of the flue gas and water can be theoretically found out using their known mass flow rates. These can be essentially used as inputs for software analysis. The solution obtained from the software is obtained as a streamline simulation. 


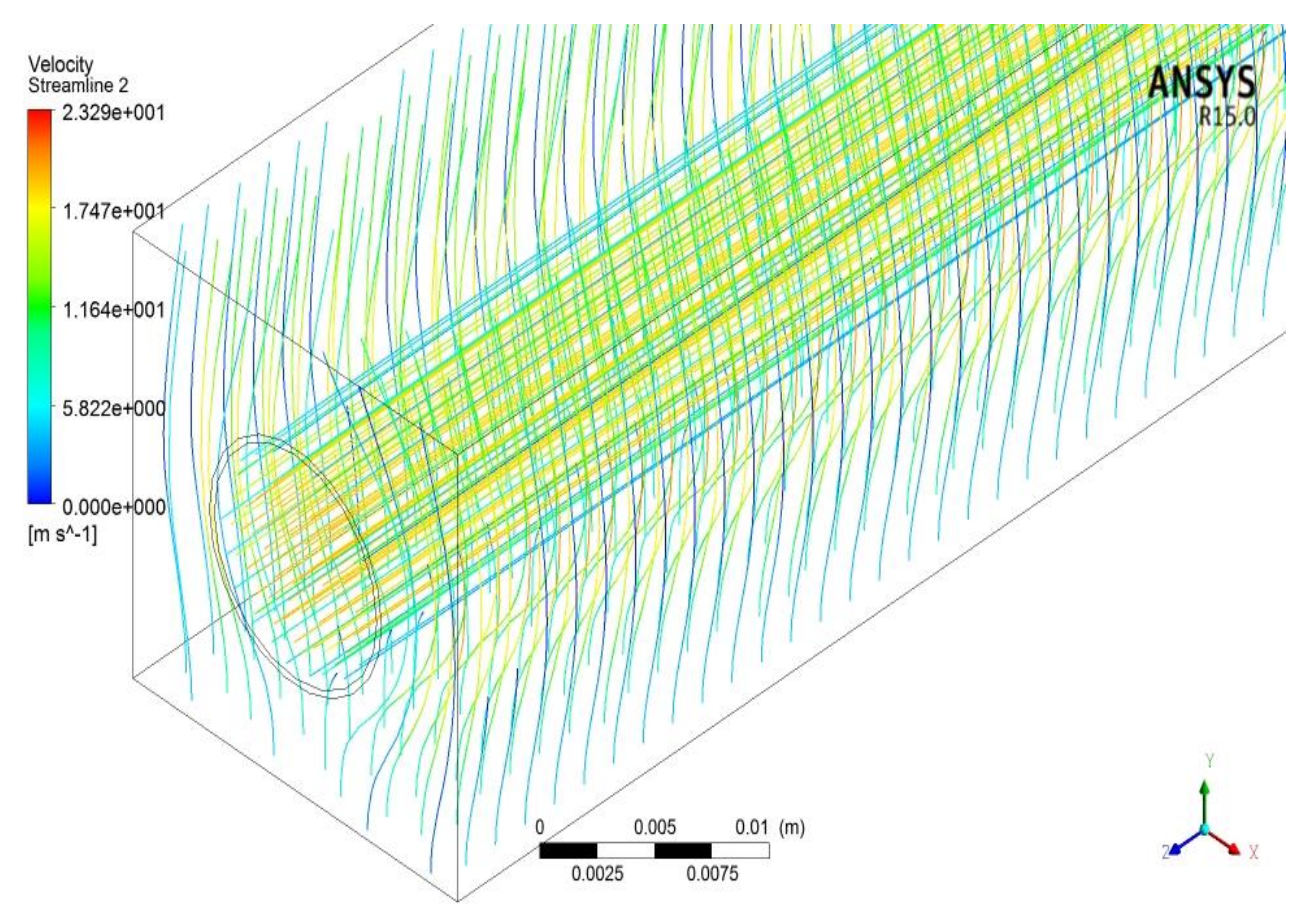

Fig. 3. Velocity streamlines of both flue gas and water

Fig. 3. shows the velocity streamlines of both flue gas and water. From the figure, it can be understood that the velocity of flue gas increases when it approaches the pipe and decreases when it passes the pipe. It may be due to, the reduction in area that occurs when the flue gas approaches the pipe and the subsequent reduction in pressure. As the flow area increases the velocity of the flue gas decreases correspondingly.
Fig. 4. shows the velocity streamline of flue gas only. From the figure it can be inferred that the velocity of the flue gas directly below the pipe is almost zero. This may be due to the near stagnation condition that arises at that region. This is mainly because of the fact that the particular layer of flue gas has less chance to escape due to the obstruction created by the pipe and the continuous collision with fresh flue gas which nearly impedes its motion. Thus there is less chance of fresh flue gas interaction with the pipe wall at this region.
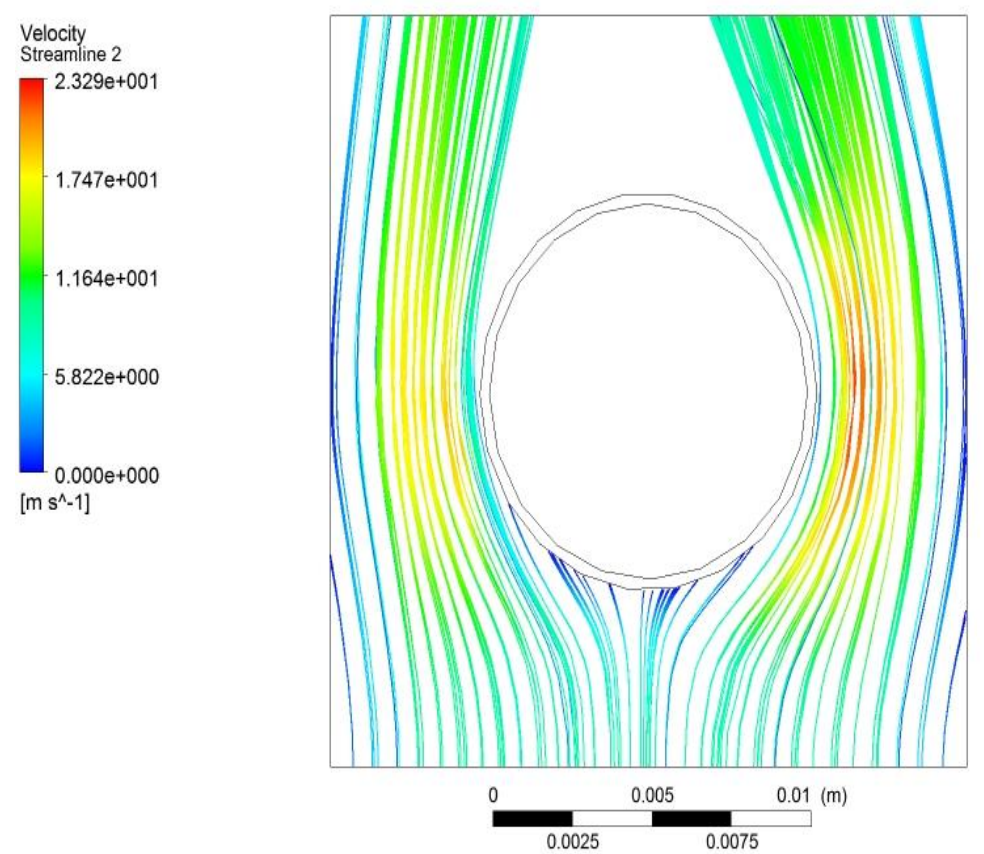

ANSYS R15.0

Fig. 4. Velocity Streamline of Flue Gas 
Fig. 5. shows the velocity contour plot of water flow at the outlet of the first pipe. The plot gives the velocity variation in the radial direction. It can also be inferred from the figure that the velocity of water layers close to the pipe boundary is low as compared to the velocity of water layer passing through the center of the pipe. This is due to the viscous effects that becomes prominent as the proximity to the pipe wall increases.
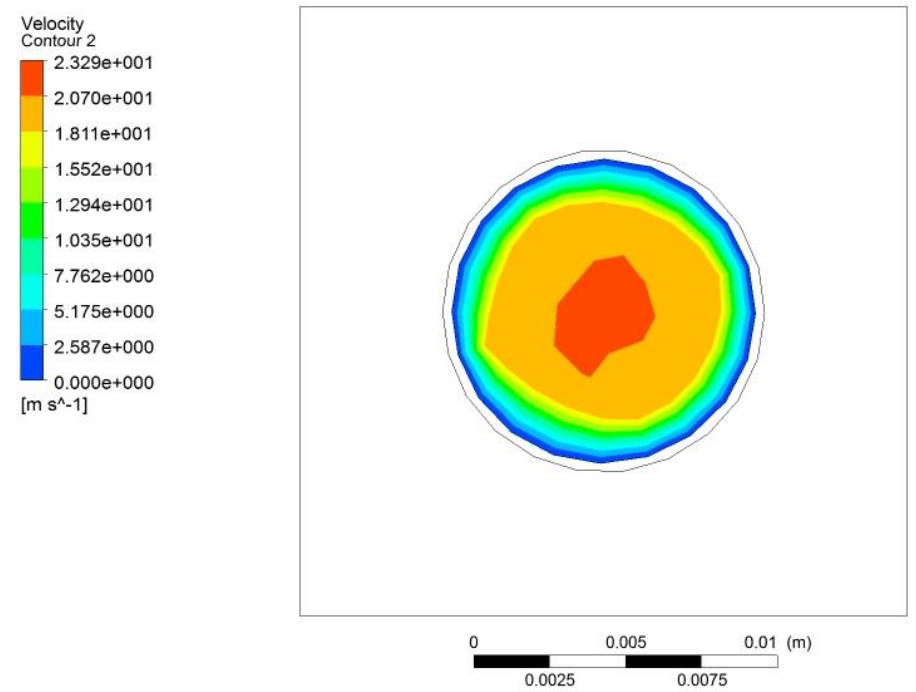

$\underset{\text { R15.0 }}{\text { ANSYS }}$

Fig. 5. Velocity contour at the outlet of pipe

The velocity analysis is the basis for all other subsequent analysis in this work. The variations in velocity is the prime determinant for the variation of properties like Temperature and Pressure all across the control volume. It is clear from the figure that although the velocities of the flue gas and water involved are small, but they are sufficient enough to bring a considerable amount of heat transfer in this work. Many works states that minimizing the pressure drop and the mass flow rate of the fluids will minimize the operating cost of the heat exchanger, but it will maximize the size of the heat exchanger and thus the initial cost. As a rule of thumb, doubling the mass flow rate will reduce the initial cost by half but will increase the pumping power requirements by a factor of roughly eight. Low velocities are helpful in avoiding erosion, tube vibrations, and noise as well as pressure drop.

\subsection{Temperature Analysis}

Temperature analysis is carried out by considering only the inner wall of the pipes 1 and 12. Other pipes are not considered. This is because all the pipes exhibit same behavior.

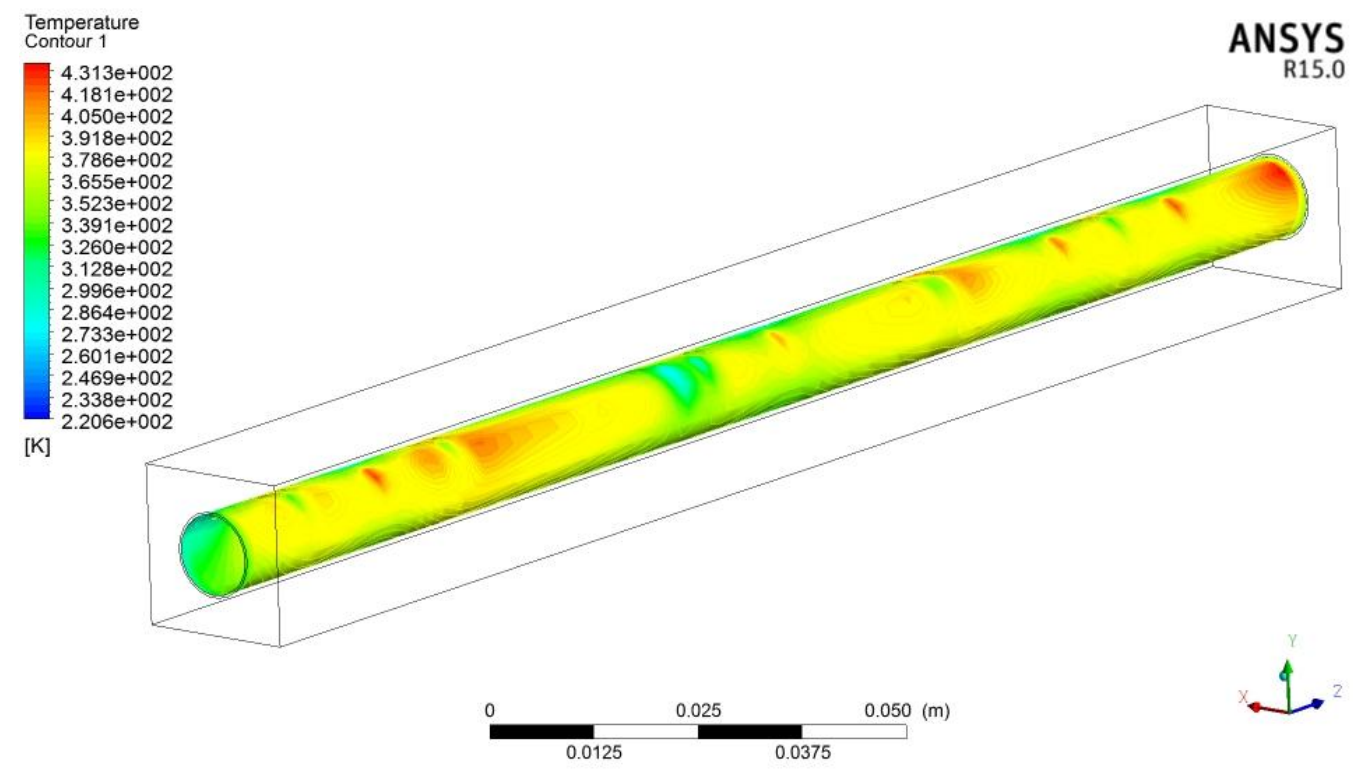

Fig. 6. Temperature contour of the inner wall of pipe 1 
Fig. 6. shows the temperature contour across inner wall of pipe 1 . From the figure we can see that top surface of pipe 1 shows higher temperature than the bottom surface or any other surface. It may be due to the vortex flow created by the flue gas due to the curved shape of the pipes, so that flue gas molecules from both sides hits the top surface of pipe. This causes higher temperature of top surface than any other surface. Temperature of the top surface is almost same as the flue gas which is at $125^{\circ} \mathrm{C}$. It is through the wall of the pipe heat passes to water inside the pipe.
Fig. 7. shows the temperature contour of inner wall of pipe 12. From this pipe we can see that temperature is same at all regions of the wall. Water enters the last pipe after passing through all the 11 pipes and the temperature of water goes on increasing as it pass through each pipe since it is a multi-pass heat exchanger. High temperature water at about $95^{\circ} \mathrm{C}$ enters into the last pipe. Since temperature of the water is very high, heat from the walls is distributed to the walls of the pipe. Also wall is heated due to temperature of flue gas. This may be the reason that inner wall of pipe has higher temperature at all its regions.

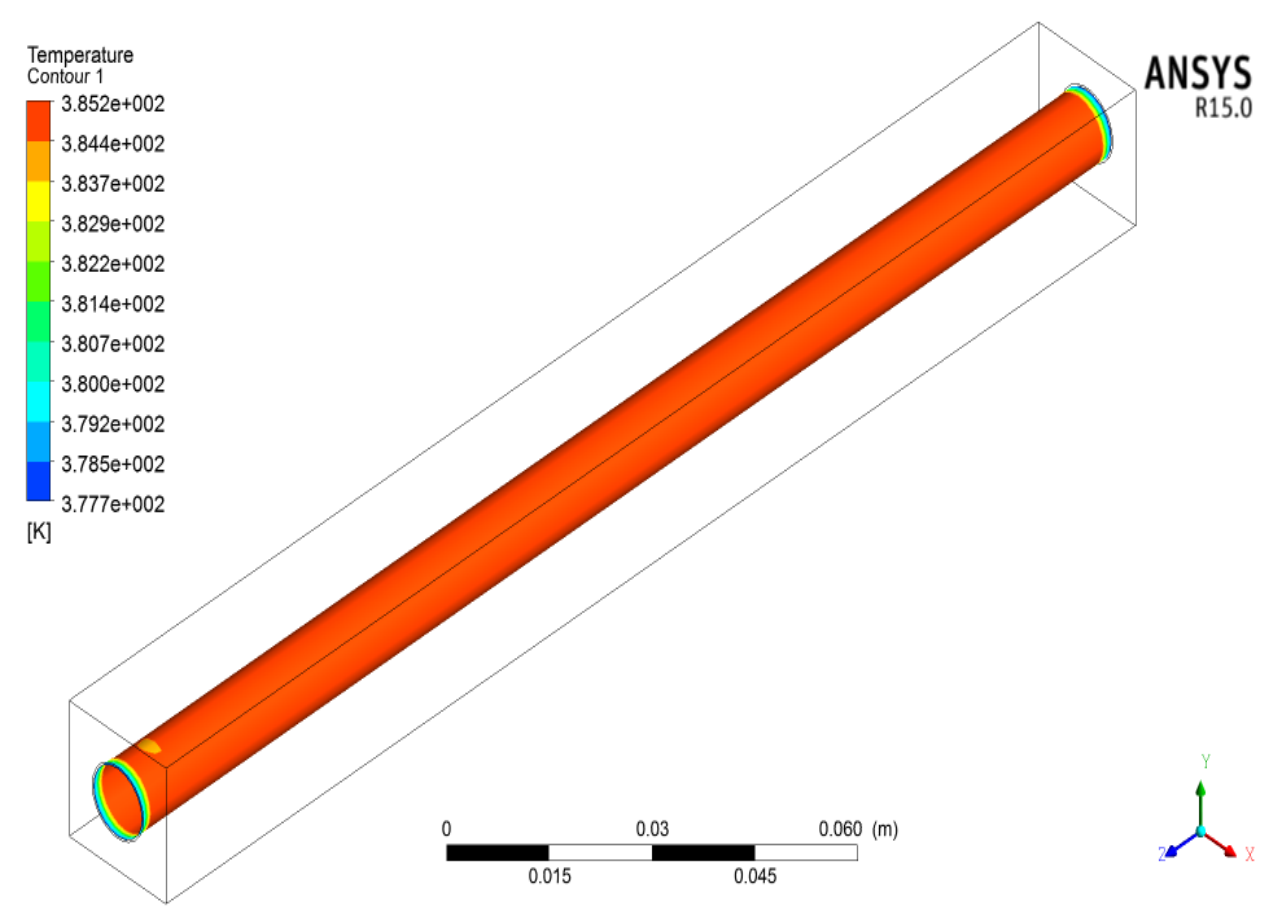

Fig. 7. Temperature contour of the inner wall of pipe 12

\section{RESULTS AND DISCUSSIONS}

\subsection{Temperature at Outlet of Each Pipe}

The temperature at the outlet of each pipe is taken as an average value of temperatures at each section considered along the radial direction. This is because the temperature at any particular section cannot represent the outlet temperature correctly. These temperatures are obtained by plotting charts at each considered section. The average temperatures at the outlet of each pipes of the heat exchanger are shown in the Table 2.

The temperature of water entering the first pipe is taken as ambient temperature, which is $300 \mathrm{~K}$. Finally at the end of the last pipe, the average outlet temperature is almost $374.1 \mathrm{~K}$. The iteration procedure is stopped at the twelfth pipe mainly due to two reasons. The first reason is that unlike all the other eleven preceding pipes the temperature rise in the twelfth pipe is a mere $2^{\circ} \mathrm{C}$ compared to five in all the other tubes, thus it is useless continuing the iteration procedure any further. The second reason is that the outlet temperature of the twelfth pipe is almost $374.1 \mathrm{~K}$ which vaporises a small quantity of water to steam which is undesirable. This value is different from the theoretical outlet temperature of water (363K). Thus along with maximum possible heat transfer, this design also provides a factor of safety for the design.

Table 2. Average outlet temperatures of different pipes.

\begin{tabular}{|l|l|l|}
\hline $\begin{array}{l}\text { Pipe } \\
\text { No. }\end{array}$ & $\begin{array}{l}\text { Inlet } \\
\text { Temperature } \\
(\mathbf{K})\end{array}$ & $\begin{array}{l}\text { Outlet } \\
\text { Temperature } \\
(\mathbf{K})\end{array}$ \\
\hline 1 & 300 & 309.6 \\
\hline 2 & 309.6 & 320.3 \\
\hline 3 & 320.3 & 325.1 \\
\hline 4 & 325.1 & 333.6 \\
\hline 5 & 333.6 & 341.4 \\
\hline 6 & 341.4 & 347.7 \\
\hline 7 & 347.7 & 353.6 \\
\hline 8 & 353.6 & 359.1 \\
\hline 9 & 359.1 & 363.6 \\
\hline 10 & 363.6 & 368 \\
\hline 11 & 368 & 371.5 \\
\hline 12 & 371.5 & 374.1 \\
\hline
\end{tabular}




\subsection{Temperature vs. Radial Distance (pipe 1)}

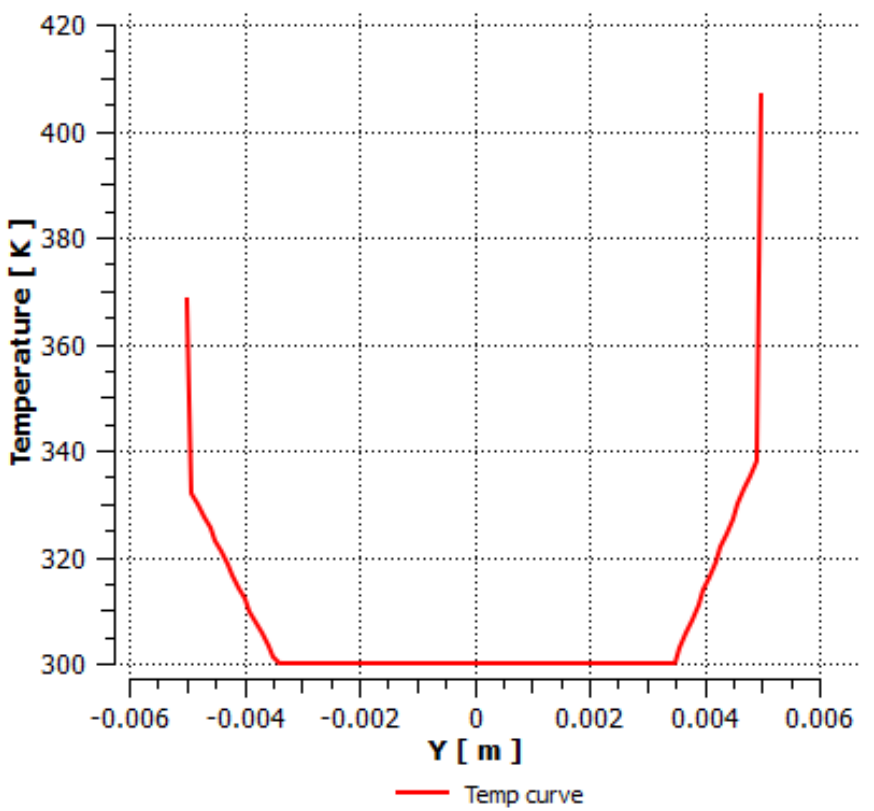

Fig. 8. Temperature variation along the radial direction at the outlet of pipe 1

The graph of Temperature vs. Radial distance at the outlet of the first pipe is shown in the Fig. 8. This chart gives an idea about the variation of temperature with radial distance above and below the axis of the pipe. From the graph it is clear that temperature is maximum at the top and bottom of the pipe and there will be almost no change in the temperature along the centre portion of the pipe $(+3.5$ to $-3.5 \mathrm{~cm})$. This may be due to the fact that the flue gas transfers its heat to the walls of the pipes and the water layer that is nearer to the boundary stays there long due to viscous effects as compared to the fluid layers at the centre and gets heated up. The velocity of the fluid layer at the center will be more thus there is less chance for heat transfer between the different layers of fluid in that region. Temperature of water layer close to the top boundary is more as compared to that of bottom layer. This may be due to the reason cited earlier i.e. the stagnation condition existing below the heat exchanger pipe. Thus the stagnant layer of flue gas prevents the transfer of heat by fresh flue gas. But the top surface will always face a fresh flue gas flow (Vortex flow) thus increasing the boundary temperature there.

\subsection{Temperature vs. Longitudinal Distance}

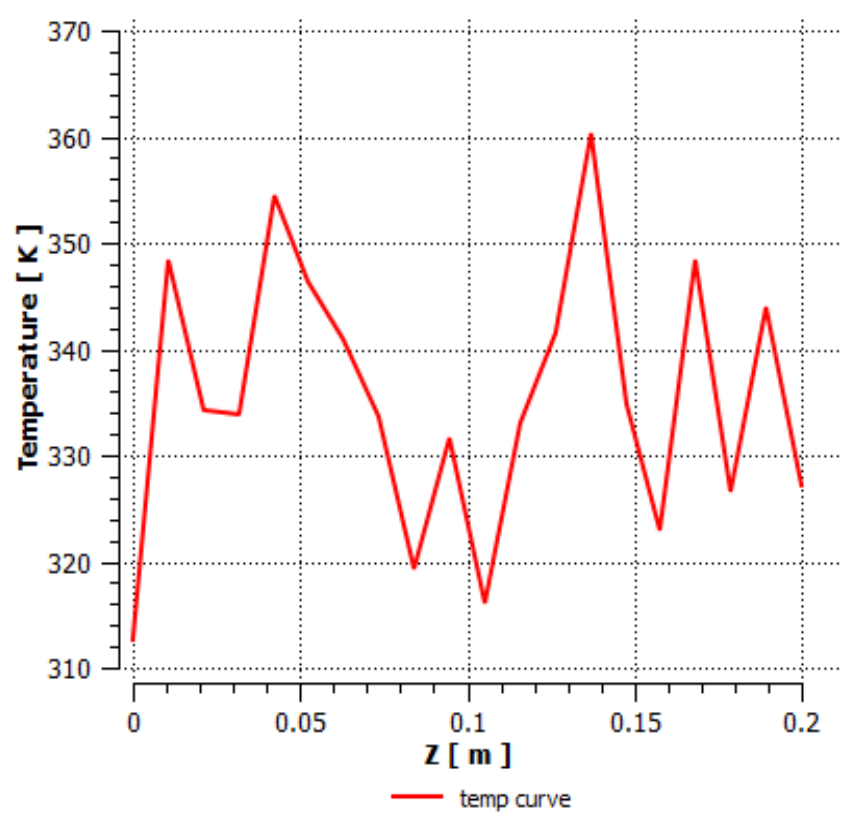

Fig. 9. Temperature variation along the length of pipe 1 close to the pipe wall

The temperature vs. longitudinal distance curve for the first pipe at a section close to the pipe wall region is shown in the Fig. 9. It shows the variation of temperature along the length of the tube. Only a single section is considered for analysis because the charts considered along different sections along the length have same trends. From the graph it is clear that, the temperature is not uniform throughout the length of the pipe. Both increase and decrease in the temperature can be seen from the chart. This may be due to the temperature gradient existing between different layers of the fluid. As a result there will be density gradient at different layers of the fluid. This causes random movement of fluid molecules thus distributing temperatures unevenly.

\subsection{Temperature vs. Radial Distance (pipe 12)}

The graph showing Temperature vs. Radial distance for the last pipe is shown in the Fig. 10. It can be easily noticed that the pattern of the curve is very much similar to the curve shown in figure 8 . Only difference is that the temperature at the top and bottom layer are comparable in this case. This may be due to the high temperature of water entering the twelfth pipe unlike the first pipe. All the other pipes will be showing similar trends like that of Fig. 8 and Fig. 9, except that there operating temperature will be different. 


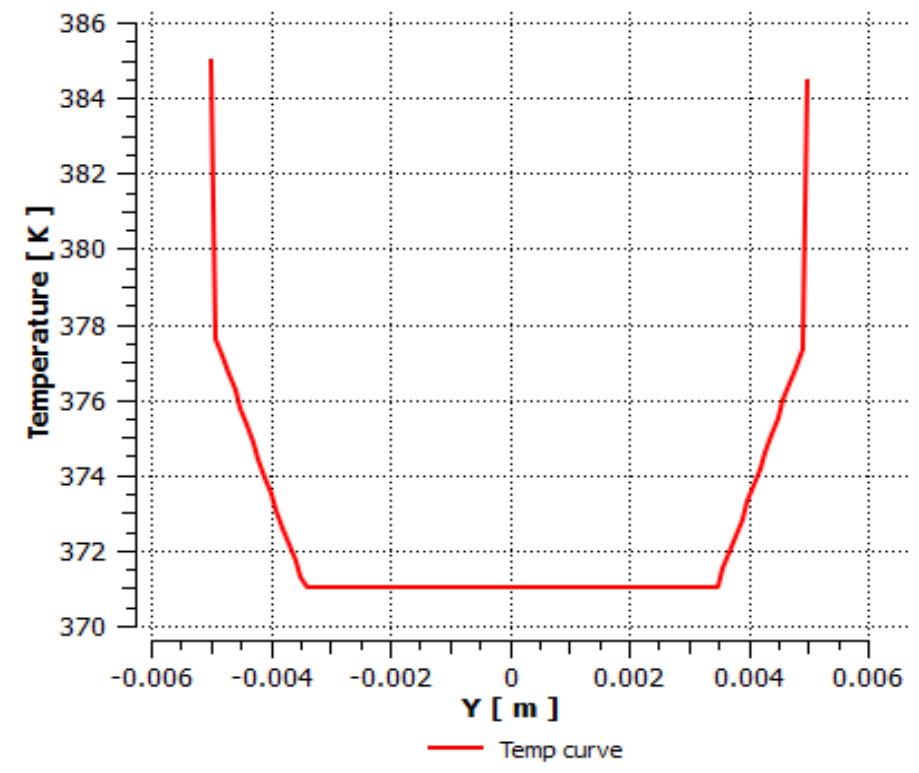

Fig. 10. Temperature variation along the radial direction at the outlet of pipe 12

\section{CONCLUSION}

As the energy demand in our day to day life escalates significantly, there are plenty of energies are shuffled in the universe. Energies are put in an order of low grade and high grade energies. The regeneration of low grade energy into some beneficial work is a fantastic job. One such low grade energy is heat energy. So it is imperative that a significant and concrete effort should be taken for using heat energy through waste heat recovery. This work focuses on tapping the unused heat energy from flue gas and using the same for day-to-day applications, in this case for air conditioning application. The main conclusion that can be drawn from this work is the relative advantage that a VAM has over the VCM. The dimensions of the final design of the heat exchanger was obtained as $0.106 \mathrm{~m} \times 2.4 \mathrm{~m} \times 3.4 \mathrm{~m}$. The finally optimized total number of pipes was 12 and it was found that further increase in the number of pipes is not justifiable because the rise in water temperature per pipe is not above $1^{\circ} \mathrm{C}$. The optimized total length and pipe diameter of the heat exchanger was obtained as $30 \mathrm{~m}$ and $0.1 \mathrm{~m}$ respectively. The required mass flow rate of water through the heat exchanger is $1.516 \mathrm{~kg} / \mathrm{sec}$ and the average outlet temperature of last pipe is $101.1{ }^{\circ} \mathrm{C}$. The temperature of water exiting the heat exchanger is potential enough to run a single effect Vapour Absorption Machine. The final proposed Vapour Absorption Machine effectively replaces the exiting Vapour Compression Machine.

\section{REFERENCES}

[1] K. Balaji and R. Senthil Kumar, "Study of Vapour Absorption System Using Waste Heat in Sugar Industry," IOSR Journal of Engineering (IOSRJEN), Volume 2, Issue 8, pp. 34-39, 2012.

[2] Ramesh K. Shah and Dusan P. Sekulic, Fundamentals of Heat Exchanger Design, John Wiley \& Sons, Inc., $1^{\text {st }}$ Edn., Hoboken, New Jersey,2003.
[3] Kuppan Thulukkanam, Heat Exchanger Design Handbook, CRC Press, $2^{\text {nd }}$ Edn., Boca Raton, 2013.

[4] R. K. Rajput, Heat and Mass Transfer, S. Chand, 5th Edn., New Delhi, 2014.

[5] R. S. Khurmi and J.K. Gupta, A Textbook of Refrigeration and Air Conditioning, S. Chand, 5th Edn., New Delhi, 2014. 